\title{
The Effect of UDMA/TEGDMA Mixtures and Bioglass Incorporation on the Mechanical and Physical Properties of Resin and Resin-Based Composite Materials
}

\author{
Laura C. Nicolae, ${ }^{1}$ Richard M. Shelton, ${ }^{1}$ Paul R. Cooper, ${ }^{1}$ \\ Richard A. Martin, ${ }^{2}$ and William M. Palin' \\ ${ }^{1}$ Biomaterials Unit, School of Dentistry, University of Birmingham, Birmingham B4 6NN, UK \\ ${ }^{2}$ School of Engineering and Applied Sciences \& Aston Research Centre for Healthy Ageing, Aston University, Birmingham B4 7ET, UK \\ Correspondence should be addressed to Laura C. Nicolae; lxn170@bham.ac.uk
}

Received 6 September 2013; Accepted 10 February 2014; Published 12 March 2014

Academic Editors: S. Deb, J. Gough, and C. Scotchford

This Conference Paper is based on a presentation given by Laura C. Nicolae at "UK Society for Biomaterials Annual Conference 2013” held from 24 June 2013 to 25 June 2013 in Birmingham, United Kingdom.

\begin{abstract}
Copyright (C) 2014 Laura C. Nicolae et al. This is an open access article distributed under the Creative Commons Attribution License, which permits unrestricted use, distribution, and reproduction in any medium, provided the original work is properly cited.

Incorporating Bioglass into dental composites may improve biocompatibility and aid tooth and bone tissue remineralisation. This study aimed to determine the impact of Bioglass and silica filler on the mechanical and physical properties of cured photopolymers. Hardness (Vickers microhardness test), flexural strength (FS), and flexural modulus (FM) (three-point bend test) of resins containing various urethane dimethacrylate (UDMA)/triethylene glycol dimethacrylate (TEGDMA) and bisphenol A-glycidyl methacrylate (bisGMA)/TEGDMA concentrations (20-80 mass\%) were tested. Degree of conversion (DC), FS, and FM of resin composites containing nonsilanised irregular 45S5-Bioglass (50 $\mathrm{m} ; 5-40 \mathrm{mass} \%)$ and/or silanised silicate glass filler particulates $(0.7 \mu \mathrm{m} ; 30-70$ mass\%) were tested. Data was analysed using one-way ANOVA. UDMA/TEGDMA resins exhibited increased hardness and FM compared with bisGMA/TEGDMA resins. Addition of Bioglass particles to 60/40 wt\% UDMA/TEGDMA or bisGMA/TEGDMA resins may enable the development of new materials that exhibit higher or at least equivalent values of DC, FS, and FM compared with conventional resin composites.
\end{abstract}

\section{Introduction}

Conventional light-cured dimethacrylate resin composites undergo free radical photopolymerisation in response to blue light (wavelength $450-500 \mathrm{~nm}$ ). The resin composites contain monomers such as bisGMA, UDMA, and TEGDMA (used as a diluent) in the organic matrix, a ketone-amine initiator/coinitiator system and inert silicate filler particles $[1,2]$. UDMA is increasingly used in the organic matrix of resin composites for dental applications [1], due to the flexibility and strength conferred by the urethane group $[2,3]$. These properties may result in enhanced physical and mechanical properties of resin-based UDMA composites compared with resins containing bulky bisGMA molecules [4]. Although conventional resin composites have been a successful restorative dental material, there is no beneficial biological interaction between the surrounding tissues and the material. By incorporating an optically suited, bioactive glass into these resins, the biocompatibility with the surrounding tissues and remineralisation processes may be improved [3].

The aim of this project was to determine the effect of mixing various comonomer base resin ratios and the impact of the incorporation of silica filler and Bioglass on the mechanical and physical properties of the cured photopolymer composite. 


\section{Methods}

2.1. Resin Synthesis. All materials were supplied by SigmaAldrich, UK, and used as received. A variety of UDMA/ TEGDMA and bisGMA/TEGDMA concentrations $(20: 80$, $30: 70,40: 60,50: 50,60: 40,70: 30$, and $80: 20$ ) were synthesised to determine the optimum polymer conversion. Camphorquinone (CQ, $0.2 \mathrm{wt} \%$ ) and a coinitiator (2 dimethylaminoethyl methacrylate; DMAEMA, $0.8 \mathrm{wt} \%$ ) were added as the photoinitiator system to the organic matrix of the resins. The resin formulations were mixed on a magnetic stirrer for $30 \mathrm{~min}$ at $60^{\circ} \mathrm{C}$ and subsequently stored in a lightproof container at $4^{\circ} \mathrm{C}$ to avoid premature photocuring.

2.2. Resin Composite Synthesis. The bioactive glass was manufactured using an established glass melt process producing the $45 \mathrm{~S} 5$ Bioglass composition of $(\mathrm{CaO})_{26.9}$ $\left(\mathrm{Na}_{2} \mathrm{O}\right)_{24.4}\left(\mathrm{SiO}_{2}\right)_{46.1}\left(\mathrm{P}_{2} \mathrm{O}_{5}\right)_{2.6} \quad$ [5]. Silica and irregular Bioglass $(<50 \mu \mathrm{m}$, passed through a $50 \mu \mathrm{m}$ sieve $)$ particles (Figure 1) were added to $60: 40 \mathrm{wt} \%$ UDMA/TEGDMA or bisGMA/TEGDMA in concentrations $70: 0,65: 5,60: 10$, $50: 20,40: 30$, and $30: 40$.

2.3. Hardness of Cured Resins. The cured surface hardness of each unfilled resin sample (10 $\mathrm{mm}$ diameter, $2 \mathrm{~mm}$ thick) was measured with a hardness tester (Duramin, Struers, UK). Each resin disc was subjected to a load of $100 \mathrm{kgf}$ for $15 \mathrm{~s}$. The size of the indentations caused by the pyramid-shaped diamond indenter on the resins disc surface was recorded. The 2 diagonals of each square were measured and an average was calculated. Equation (1) was employed to calculate the Vickers hardness number:

$$
\mathrm{HV}=\frac{1.854 F}{d^{2}}\left(\mathrm{kgf} / \mathrm{mm}^{2}\right)
$$

where $\mathrm{HV}$ is Vickers hardness number, $F$ is force applied to the specimen, and $d^{2}$ is surface area determined by taking the average of the 2 diagonals of the square left by the indenter [6].

2.4. Degree of Conversion of Resin Composites. The degree of conversion (DC) of resin composite samples was measured statically using a Fourier transform near-infrared technique (4 scans; 8 wave number resolution; Nicolet 6700, Thermoscientific) [7]. The resin composite mixture was exposed to curing light for $40 \mathrm{~s}$ (Optilux 501, wavelength maxima $470 \mathrm{~nm}$; irradiance $850 \mathrm{~mW} / \mathrm{cm}^{2}$ ).

2.5. Flexural Strength and Modulus of Resins and Resin Composites. Rectangular bars ( $25 \mathrm{~mm}$ length, $2 \mathrm{~mm}$ breadth, and $2 \mathrm{~mm}$ thickness) of 60/40 U/T and $\mathrm{B} / \mathrm{T}$ resins and each resin composite were polymerised using an overlapping curing protocol with a $12 \mathrm{~mm}$ diameter curing tip for $40 \mathrm{~s}$. FS and FM of resin composite samples $(25 \times 2 \times 2 \mathrm{~mm})$ were determined using the three-point bend test by subjecting each resin bar to loading using a universal testing machine (Instron 5544, UK) at a cross head speed of $1 \mathrm{~mm} / \mathrm{min}$ and $1 \mathrm{kN}$ load. FS of resin samples was calculated using

$$
\mathrm{FS}=\frac{3 P L}{2 b d}
$$

FM of resin samples was calculated using

$$
\mathrm{FM}=\frac{(3 P L / 2 b d)}{\left(6 D d / L^{2} * 100\right)},
$$

where $P$ is load at fracture, $L$ is support span, $b$ is specimen width, $d$ is specimen thickness, and $D$ is midspan deflection [8].

One-way ANOVA and post hoc Tukey tests were used to determine significant differences between sample conditions (95\% significance level).

\section{Results}

3.1. Unfilled Resins. Resins containing bisGMA/TEGDMA exhibited significantly decreased values for hardness (Figure 1), FS, and FM (Table 1) compared with UDMA/ TEGDMA resins $(P<0.005)$. For bisGMA/TEGDMA resins, $60 / 40$ wt $\%$ ratio exhibited significantly higher hardness values compared with the other formulations $(P<0.005)$ (Figure 1). Resins containing 50/50, 60/40, and 70/30 wt $\%$ UDMA/TEGDMA exhibited significantly higher hardness values compared with any other UDMA/TEGDMA mixture $(P<0.001)$ (Figure 1).

The FS and FM of $50 / 50,60 / 40$, and $70 / 30 \mathrm{wt} \%$ UDMA/TEGDMA- and bisGMA/TEGDMA-based resins were significantly higher compared with the other formulations $(P<0.005)$ (Table 1$)$. Resins containing 50/50, 60/40, and 70/30 wt\% UDMA/TEGDMA mixtures exhibited significantly higher FS values compared with resins containing 50/50, 60/40, and 70/30 wt $\%$ bisGMA/TEGDMA mixtures (Table 1).

The optimum concentration of bisGMA/TEGDMA and UDMA/TEGDMA based on DC (data not shown), hardness (Figure 1), FS, and FM (Table 1) was determined to be $60 / 40 \mathrm{wt} \%$. Therefore, this concentration was used for Bioglass addition experiments.

3.2. Resin Composites. The DC of bisGMA/TEGDMA-based resins containing $20 \mathrm{wt} \%$ Bioglass was significantly higher compared with the other bisGMA/TEGDMA-based resin composites $(P<0.05)$. Although UDMA/TEGDMA-based resin composites containing $20 \mathrm{wt} \%$ Bioglass exhibited the highest DC, it was not significantly different compared with the other UDMA/TEGDMA-based resin composites $(P>0.1)$ (Figure 2). The addition of $5 \mathrm{wt} \%$ Bioglass resulted in a decrease in the DC of composites compared with unfilled resins; however, no additional decrease was observed up to 30 wt $\%$ Bioglass (Figure 2).

FS and FM of bisGMA/TEGDMA resin composites containing $20 \mathrm{wt} \%$ Bioglass were significantly higher compared with bisGMA/TEGDMA composites containing $70 \mathrm{wt} \%$ silica $(P<0.005)$ (Table 2$)$. There was no significant difference 
TABLE 1: Flexural strength and modulus of bisGMA/TEGDMA (BT) and UDMA/TEGDMA (UT) resins. UDMA/TEGDMA resins exhibited increased flexural modulus compared with bisGMA/TEGDMA resins. Standard deviation $(n=9)$ is displayed in paranthesis.

\begin{tabular}{|c|c|c|c|c|c|}
\hline BisGMA/TEGDMA (wt\%) & FS (MPa) & $\mathrm{FM}(\mathrm{GPa})$ & UDMA/TEGDMA (wt\%) & $\mathrm{FS}(\mathrm{MPa})$ & $\mathrm{FM}(\mathrm{GPa})$ \\
\hline $20: 80 \mathrm{BT}$ & $50.9(4.7)$ & $1.4(0.0)$ & $20: 80 \mathrm{UT}$ & $43.9(7.9)$ & $1.2(0.1)$ \\
\hline $30: 70 \mathrm{BT}$ & $59.4(9.6)$ & $1.8(0.3)$ & $30: 70 \mathrm{UT}$ & $64.1(6.0)$ & $1.6(0.1)$ \\
\hline $40: 60 \mathrm{BT}$ & $61.0(4.9)$ & $1.7(0.1)$ & $40: 60 \mathrm{UT}$ & $65.4(11)$ & $1.7(0.2)$ \\
\hline $50: 50 \mathrm{BT}$ & $66.2(4.1)$ & $1.9(0.1)$ & $50: 50 \mathrm{UT}$ & $77.5(5.3)$ & $2.0(0.1)$ \\
\hline $60: 40 \mathrm{BT}$ & $64.7(3.7)$ & $1.7(0.1)$ & $60: 40 \mathrm{UT}$ & $70.8(4.1)$ & $1.9(0.0)$ \\
\hline $70: 30 \mathrm{BT}$ & $67.4(8.0)$ & $1.7(0.1)$ & $70: 30 \mathrm{UT}$ & $74.0(7.2)$ & $2.0(0.2)$ \\
\hline $80: 20 \mathrm{BT}$ & $55.2(4.8)$ & $1.5(0.1)$ & $80: 20 \mathrm{UT}$ & $69.0(6.5)$ & $1.7(0.1)$ \\
\hline
\end{tabular}

TABLE 2: The FS and FM of bisGMA/TEGDMA and UDMA/TEGDMA resin composites. UDMA/TEGDMA- based composites exhibited higher FS and FM compared with bisGMA/TEGDMA-based composites. BG: Bioglass. Standard deviation $(n=9)$ is displayed in parenthesis.

\begin{tabular}{|c|c|c|c|c|c|}
\hline $\begin{array}{l}60: 40 \text { wt } \% \\
\text { BisGMA/TEGDMA }\end{array}$ & FS (MPa) & $\mathrm{FM}(\mathrm{GPa})$ & $\begin{array}{c}60: 40 \mathrm{wt} \% \\
\text { UDMA/TEGDMA }\end{array}$ & $\mathrm{FS}(\mathrm{MPa})$ & $\mathrm{FM}(\mathrm{GPa})$ \\
\hline 70 wt $\%$ Silica & $46.1(9.4)$ & $4.8(0.5)$ & $70 \mathrm{wt} \%$ Silica & $84.3(14)$ & $7.0(0.9)$ \\
\hline 5 wt $\%$ BG & $59.4(6.4)$ & $5.9(0.2)$ & $5 \mathrm{wt} \% \mathrm{BG}$ & $80.3(7.2)$ & $6.4(0.5)$ \\
\hline $10 \mathrm{wt} \% \mathrm{BG}$ & $55.1(5.5)$ & $5.4(0.4)$ & $10 \mathrm{wt} \% \mathrm{BG}$ & $69.7(9.8)$ & $6.0(0.6)$ \\
\hline $20 \mathrm{wt} \% \mathrm{BG}$ & $56.5(5.1)$ & $6.8(0.4)$ & $20 \mathrm{wt} \% \mathrm{BG}$ & $79.3(8.4)$ & $6.9(0.9)$ \\
\hline $30 \mathrm{wt} \% \mathrm{BG}$ & $39.6(5.3)$ & $5.7(0.7)$ & $30 \mathrm{wt} \% \mathrm{BG}$ & $57.8(9.4)$ & $4.4(0.4)$ \\
\hline $40 \mathrm{wt} \% \mathrm{BG}$ & $26.0(3.0)$ & $3.3(0.9)$ & $40 \mathrm{wt} \% \mathrm{BG}$ & $42.7(2.9)$ & $3.6(0.5)$ \\
\hline
\end{tabular}

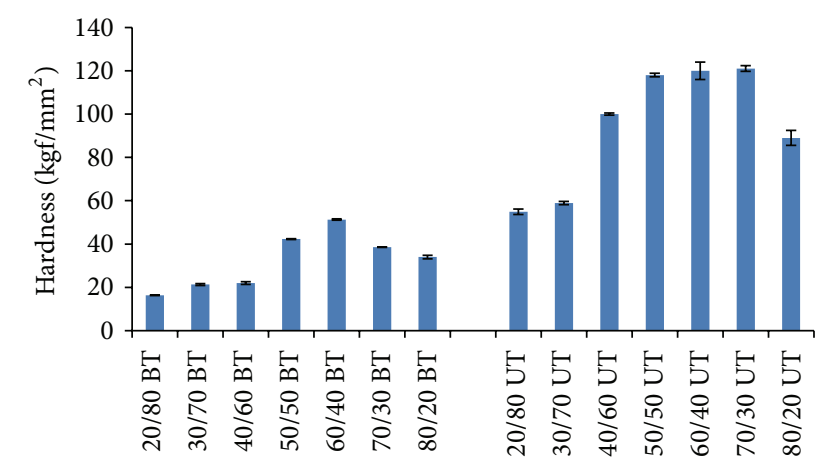

FIGURE 1: The hardness of bisGMA/TEGDMA- (BT-) and UDMA/ TEGDMA- (UT-) based resins. UDMA/TEGDMA resins exhibited increased hardness values compared with bisGMA/TEGDMA resins. Error bars represent standard deviation $(n=9)$.

in the FS and FM of UDMA/TEGDMA composites containing $70 \mathrm{wt} \%$ silica and UDMA/TEGDMA composites containing $20 \mathrm{wt} \%$ Bioglass $(P=0.673)$ (Table 2$)$. However addition of $>20 \mathrm{wt} \%$ Biglass to both bisGMA/TEGDMA- and UDMA/ TEGDMA-based resin composites resulted in a marked decrease in FS, which was significantly lower compared with the other bisGMA/TEGDMA and UMDA/TEGDMA resin composites $(P<0.005)$ (Table 2$)$.

Figure 3 shows the fracture surface of the $60 / 40 \mathrm{wt} \%$ $\mathrm{U} / \mathrm{T}$ containing $20 \mathrm{wt} \%$ and $30 \mathrm{wt} \%$ Bioglass. There is some evidence of filler "plucking" and filler "shearing," which may suggest that more energy is required for crack propagation.

The addition of up to $30 \mathrm{wt} \%$ Bioglass to bisGMA/ TEGDMA and UDMA/TEGDMA resin composites had no detrimental effect on the DC (Figure 3), whereas

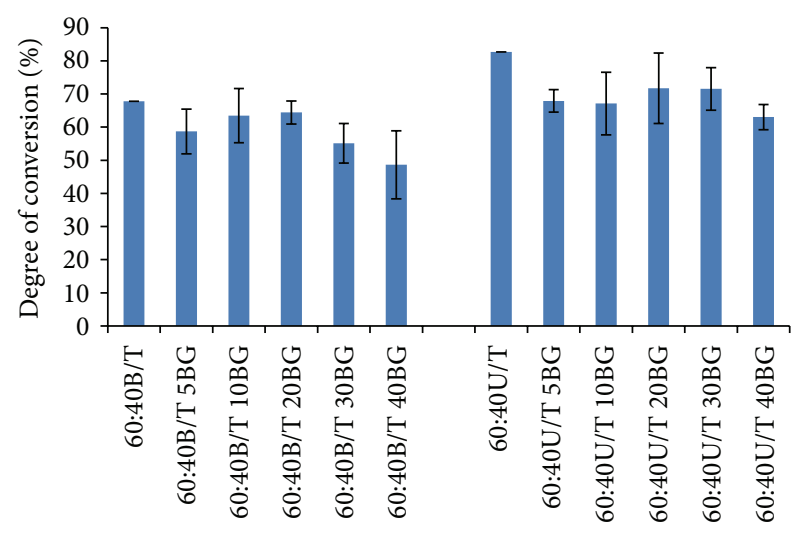

FIGURE 2: The degree of conversion of bisGMA/TEGDMA (BT) and UDMA/TEGDMA (UT) resin composites. UDMA/TEGDMAbased composites exhibited higher degree of conversion values compared with bisGMA/TEGDMA-based composites $(P<0.005$, one-way ANOVA). Error bars represent standard deviation $(n=5)$. BG: Bioglass.

the addition of $>20 \mathrm{wt} \%$ Bioglass to either bisGMA/ TEGDMA or UDMA/TEGDMA resin composites had a negative impact on the FS and FM of the final composites (Table 2).

\section{Discussion}

The molecular structure and viscosity of the comonomer mixtures significantly affect the mechanical and physical properties of the cured resin. Due to the rigidity of bisGMA molecules, polymer conversion is limited prior to the 


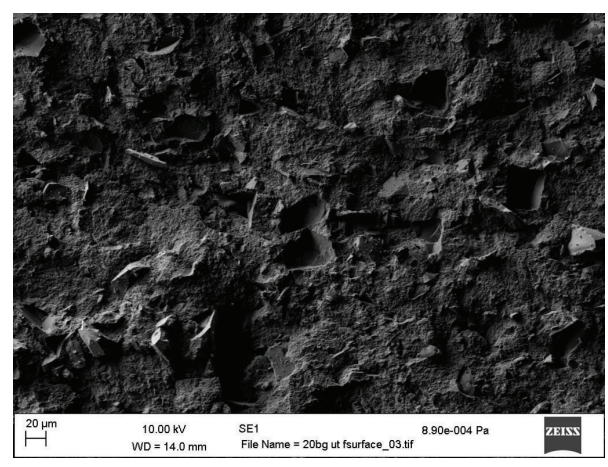

(a)

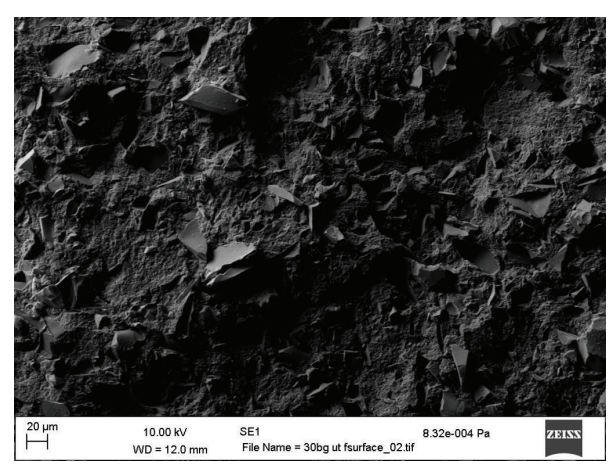

(b)

FIGURE 3: SEM micrographs of fracture surface of resin composites containing $20 \mathrm{wt} \%$ (a) and $30 \mathrm{wt} \%$ (b) Bioglass at 500x magnification.

maximum rate of polymerisation, which limits propagation reactions. The lower viscosity and increased flexibility of UDMA at early stages of polymerisation (controlled by differences in hydrogen bonding interactions and molecular structure) will lead to higher conversion prior to diffusioncontrolled propagation $[9,10]$ and thus higher final DC and network formation evidenced by significantly increased hardness (Figure 1). Thus, the optimum concentration of bisGMA/TEGDMA and UDMA/TEGDMA based on DC, RP (data not shown), hardness (Figure 1), FS, and FM (Table 1) was determined to be $60 / 40 \mathrm{wt} \%$.

The addition of Bioglass particles reduced the DC of the resin composites compared with the unfilled resins, which was possibly due to particle size, morphology, and increased light attenuation (reflection, refraction, and scattering) and opacity during the polymerisation reaction (Figure 2).

The UDMA/TEGDMA-based resin composites exhibited higher FS and FM values compared with bisGMA/ TEGDMA-based composites (Table 2), which is also likely to be a result of increased crosslink density in the polymer network. Increasing Bioglass content ( $>20 \mathrm{wt} \%)$ within the matrix had a detrimental effect on the optical characteristics, which led to a reduction in DC and consequently FS and FM.

At the fracture surface (Figure 3), there is some evidence of filler "plucking" that would be expected for the incorporation of Bioglass fillers without surface modification using a silane agent to achieve a chemical bond between the filler and matrix. There may also be some filler "shearing" at the fracture surface, which may require more energy for crack propagation thus leading to increased fracture toughness values (not measured), which requires further analysis. For composites containing up to $20 \mathrm{wt} \%$ Bioglass no significant deterioration in FS and FM was observed (Table 2). However, lack of filler silanisation may result in significant strength deterioration for composites containing greater than $20 \mathrm{wt} \%$ Bioglass. This will remain an important consideration in the development of "bioactive" lightcurable resin-based composites where a compromise may exist between ion dissolution/remineralisation potential and strength characteristics of the restorative material. Although $60 / 40$ comonomer mixtures exhibit the most desirable polymerisation characteristics, there exist competing factors associated with viscosity (affecting rheology and handling properties) and optical property combinations with the filler (affecting refractive index and light transmission through depth), which require further consideration.

\section{Conclusion}

Addition of Bioglass particles to 60/40 wt $\%$ UDMA/ TEGDMA or bisGMA/TEGDMA resins may lead to the development of new materials that exhibit higher or at least equivalent values of DC, FS, and FM compared with conventional resin composites. Further work in this area is warranted.

\section{Conflict of Interests}

The authors declare that there is no conflict of interests regarding the publication of this paper.

\section{References}

[1] S. Bouillaguet, "Biological risks of resin-based materials to the dentin-pulp complex," Critical Reviews in Oral Biology and Medicine, vol. 15, no. 1, pp. 47-60, 2004.

[2] E. Asmussen and A. Peutzfeldt, "Influence of UEDMA, BisGMA and TEGDMA on selected mechanical properties of experimental resin composites," Dental Materials, vol. 14, no. 1, pp. 5156, 1998.

[3] S. Sauro, R. Osorio, R. Fulgencio et al., "Remineralisation properties of innovative light-curable resin-based dental materials containing bioactive micro-filler," Journal of Materials Chemistry B, vol. 1, no. 1, pp. 2624-2638, 2013.

[4] F. Goņalves, Y. Kawano, C. Pfeifer, J. W. Stansbury, and R. R. Braga, "Influence of BisGMA, TEGDMA, and BisEMA contents on viscosity, conversion, and flexural strength of experimental resins and composites," European Journal of Oral Sciences, vol. 117, no. 4, pp. 442-446, 2009.

[5] R. A. Martin, H. Twyman, D. Qiu, J. C. Knowles, and R. J. Newport, "A study of the formation of amorphous calcium phosphate and hydroxyapatite on melt quenched Bioglass using surface sensitive shallow angle X-ray diffraction," Journal of Materials Science, vol. 20, no. 4, pp. 883-888, 2009.

[6] A. Della Bona, V. Rosa, and D. Cecchetti, "Influence of shade and irradiation time on the hardness of composite resins," Brazilian Dental Journal, vol. 18, no. 3, pp. 231-234, 2007. 
[7] M. Hadis, J. G. Leprince, A. C. Shortall, J. Devaux, G. Leloup, and W. M. Palin, "High irradiance curing and anomalies of exposure reciprocity law in resin-based materials," Journal of Dentistry, vol. 39, no. 8, pp. 549-557, 2011.

[8] W. M. Palin, G. J. P. Fleming, and P. M. Marquis, “The reliability of standardized flexure strength testing procedures for a lightactivated resin-based composite," Dental Materials, vol. 21, no. 10, pp. 911-919, 2005.

[9] N. Moszner, U. K. Fischer, J. Angermann, and V. Rheinberger, "A partially aromatic urethane dimethacrylate as a new substitute for Bis-GMA in restorative composites," Dental Materials, vol. 24, no. 5, pp. 694-699, 2008.

[10] S. H. Dickens, J. W. Stansbury, K. M. Choi, and C. J. E. Floyd, "Photopolymerization kinetics of methacrylate dental resins," Macromolecules, vol. 36, no. 16, pp. 6043-6053, 2003. 

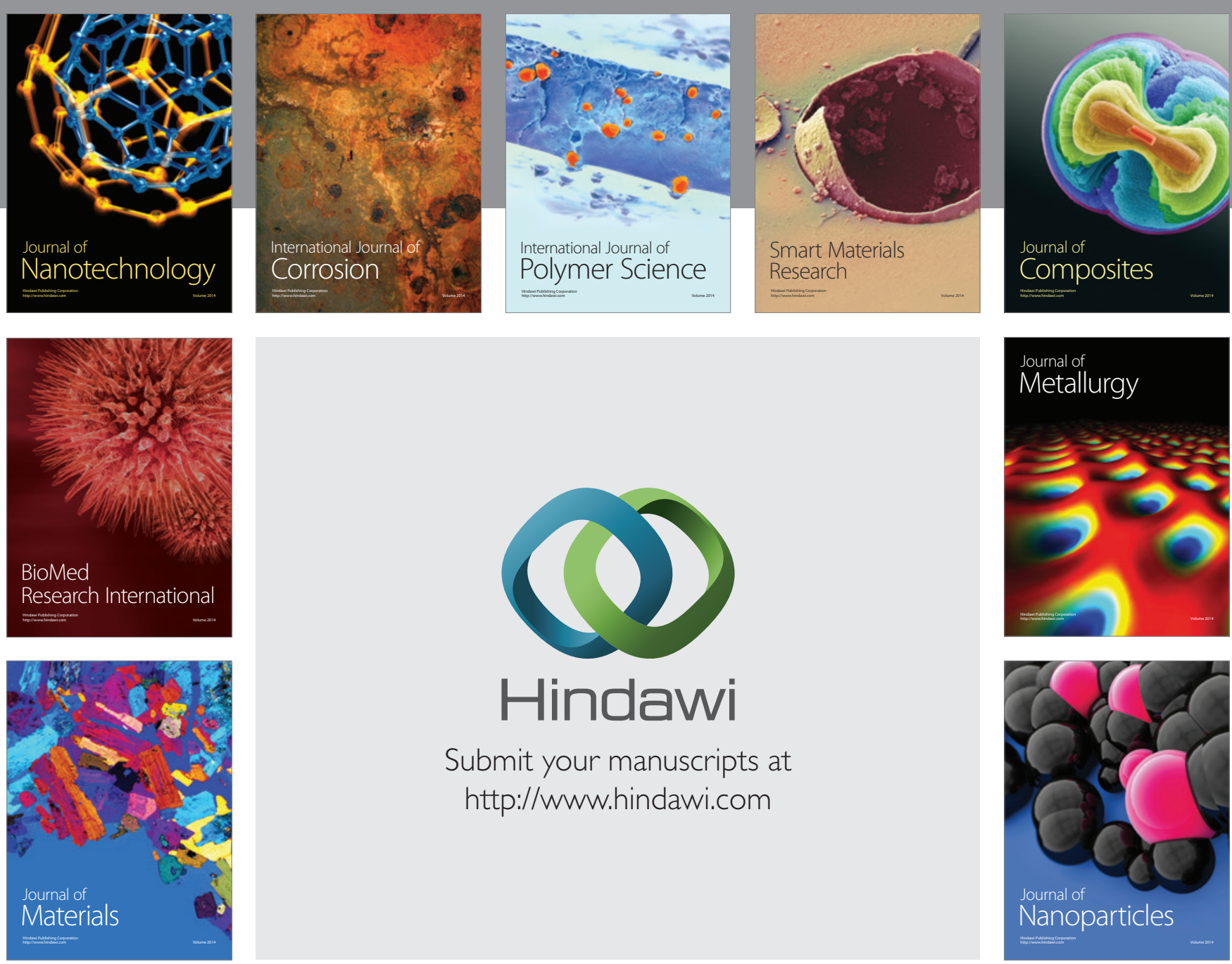

Submit your manuscripts at http://www.hindawi.com
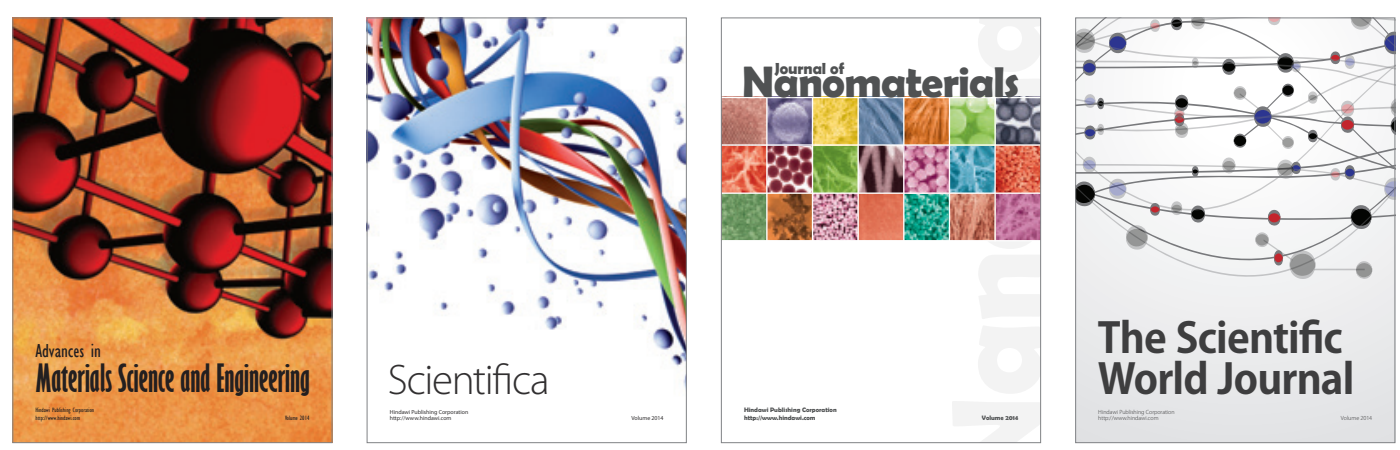

\section{The Scientific World Journal}
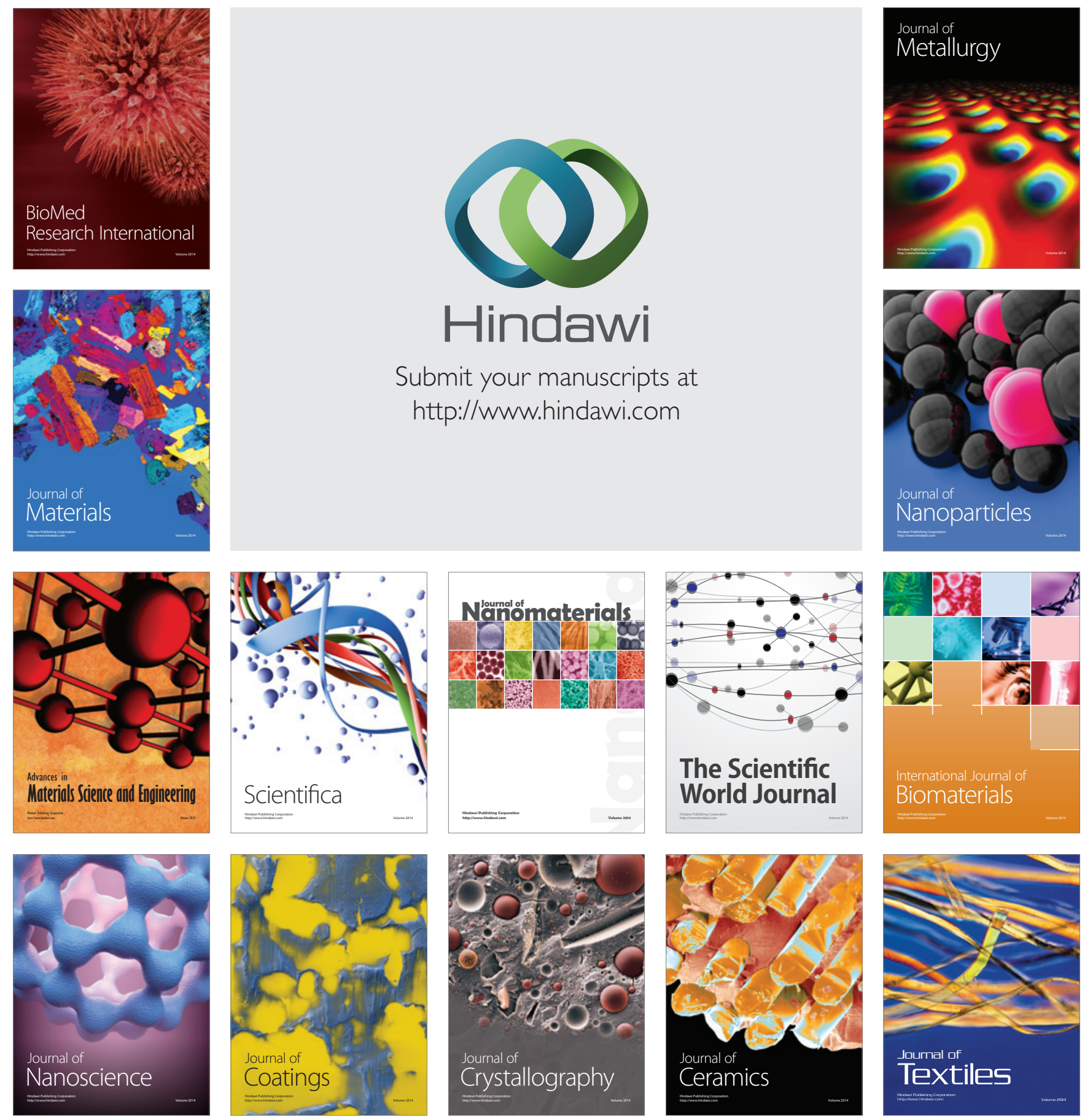